\title{
What is the evidence for the management of patients along the pathway from the emergency department to acute admission to reduce unplanned attendance and admission? An evidence synthesis
}

\author{
Sarah H. Credé ${ }^{1,4^{*}}$, Colin O'Keeffe ${ }^{1}$, Suzanne Mason ${ }^{1}$, Anthea Sutton ${ }^{1}$, Emma Howe ${ }^{1}$, Susan J. Croft ${ }^{2}$
} and Mike Whiteside ${ }^{3}$

\begin{abstract}
Background: Globally, the rate of emergency hospital admissions is increasing. However, little evidence exists to inform the development of interventions to reduce unplanned Emergency Department (ED) attendances and hospital admissions. The objective of this evidence synthesis was to review the evidence for interventions, conducted during the patient's journey through the ED or acute care setting, to manage people with an exacerbation of a medical condition to reduce unplanned emergency hospital attendance and admissions.

Methods: A rapid evidence synthesis, using a systematic literature search, was undertaken in the electronic data bases of MEDLINE, EMBASE, CINAHL, the Cochrane Library and Web of Science, for the years 2000-2014. Evidence included in this review was restricted to Randomised Controlled Trials (RCTs) and observational studies (with a control arm) reported in peer-reviewed journals. Studies evaluating interventions for patients with an acute exacerbation of a medical condition in the ED or acute care setting which reported at least one outcome related to ED attendance or unplanned admission were included.

Results: Thirty papers met our inclusion criteria: 19 intervention studies (14 RCTs) and 11 controlled observational studies. Sixteen studies were set in the ED and 14 were conducted in an acute setting. Two studies (one RCT), set in the ED were effective in reducing ED attendance and hospital admission. Both of these interventions were initiated in the ED and included a post-discharge community component. Paradoxically 3 ED initiated interventions showed an increase in ED re-attendance. Six studies (1 RCT) set in acute care settings were effective in reducing: hospital admission, ED re-attendance or re-admission (two in an observation ward, one in an ED assessment unit and three in which the intervention was conducted within $72 \mathrm{~h}$ of admission).
\end{abstract}

Conclusions: There is no clear evidence that specific interventions along the patient journey from ED arrival to $72 \mathrm{~h}$ after admission benefit ED re-attendance or readmission. Interventions targeted at high-risk patients, particularly the elderly, may reduce ED utilization and warrant future research. Some interventions showing effectiveness in reducing unplanned ED attendances and admissions are delivered by appropriately trained personnel in an environment that allows sufficient time to assess and manage patients.

Keywords: Emergency medicine, Unplanned attendance, Avoidable admissions

\footnotetext{
* Correspondence: s.h.crede@sheffield.ac.uk

'School of Health and Related Research (ScHARR), The University of Sheffield,

Sheffield, England

${ }^{4}$ School of Health and Related Research (SCHARR), The University of Sheffield,

Regent Court, Regent Street, Sheffield S1 4DA, UK

Full list of author information is available at the end of the article
} 


\section{Background}

The year-on-year increase in emergency hospital admissions creates additional pressure on health systems internationally and is a trend that is not abating. In the last 15 years these admissions have increased in England by $47 \%$ [1]. Admission rates are known to vary widely between healthcare systems [2], the majority of this variation is explained by unemployment rates and urban/ rural status, however some variation is explained by factors that are modifiable within healthcare services [3]. Healthcare service related factors associated with higher rates of potentially avoidable admissions included those related to the patient pathway from the emergency department (ED) to acute admission, i.e. ED attendance rate, the conversion rate of ED attendances to admissions as well as the proportion of short stay admissions [3]. Short stay admissions are often managed in designated assessment or observation wards/units to reduce crowding in EDs and avoid unplanned admissions [4].

A previous review suggests that there is insufficient evidence for interventions that reduce unplanned hospital admission in secondary emergency and acute settings [5]. Patients arriving in the ED will typically be assessed, managed, discharged home or admitted to hospital. Prior to admission to a hospital ward, this pathway may also involve assessment and management in an acute medical unit, typically for 24 to $72 \mathrm{~h}$ [4]. Along this patient journey surprisingly little evidence exists to inform the development of interventions to reduce unplanned hospital admissions and attendances at the ED. Management within the ED, acute assessment and observation units is key in establishing how to optimise care to reduce unnecessary variation in emergency admissions across urgent care systems.

This study reviewed the evidence on interventions to manage people with medical presentations, including those with long-term conditions and the frail elderly, who present with an acute event to reduce unplanned emergency hospital attendance and admissions. This review focusses specifically on the patient pathway from the ED to admission, including the observation ward or acute assessment unit, and uses ED attendance, re-attendance, as well as hospital admission as primary outcome measures.

\section{Methods}

A rapid evidence synthesis, using a systematic literature search, was undertaken. The search was further enhanced by supplementary search methods. As this was an evidence synthesis, following systematic review methodology, ethical approval and consent were not required.

\section{Search strategy}

Electronic data bases of MEDLINE, EMBASE, CINAHL; The Cochrane Library and Web of Science were searched, using a pre-determined search strategy, for the years 2000 - current (2014). Search terms relating to emergency medical services or acute care, medical assessment or clinical decision units, avoidable admissions or re-attendance, demand/burden on health services, chronic disease, long-term conditions, comorbidities, and the aged, were combined into a single search strategy which was translated across the five bibliographic databases listed above. Searches were limited to all adults (16 plus years) and English language publications only. Comments, letters and editorials were excluded as publication types from the search. Supplementary searches included citation searching of key references and a thorough review of reference lists of included papers and published reviews. Experts within the field of emergency and acute medicine were also consulted for additional references.

\section{Selection criteria}

Evidence included in this review was restricted to controlled and observational studies in peer-reviewed journals. Articles reporting on interventions to reduce unnecessary or avoidable unplanned ED/hospital care in emergency departments and acute medical units or acute care settings were included. Acute medical units receive patients from emergency departments for expedited specialist assessment and treatment for a period of 24-72 h before discharge or ward transfer [4]. As not all hospitals have acute medical units it was decided that any study reporting an intervention that began within $72 \mathrm{~h}$ of ED attendance or hospital admission would be included. Acknowledging that many interventions occur along the patient's clinical pathway and include important assessments before, and patient management after, the attendance we included interventions that occur within the ED, acute medical units or acute care settings or those that span these settings.

To be eligible for inclusion the study needed to report at least one outcome related to attendance at the ED, reattendance or unplanned admission to hospital. These outcomes did not have to be the primary outcome of the studies to be eligible for inclusion; although in some papers they will have been. Where the primary outcome was to reduce admissions or re-attendance this is indicated in the summary Tables 1 and 2 . The definitions of the study outcomes provided by the study authors were, in many instances, insufficient to determine whether re-attendances or readmissions included all presentations, for any presenting condition, within the defined time period or only those for the same unresolved problem. Every attempt was made to identify whether re-attendances and readmissions were related to the original episode of care. 


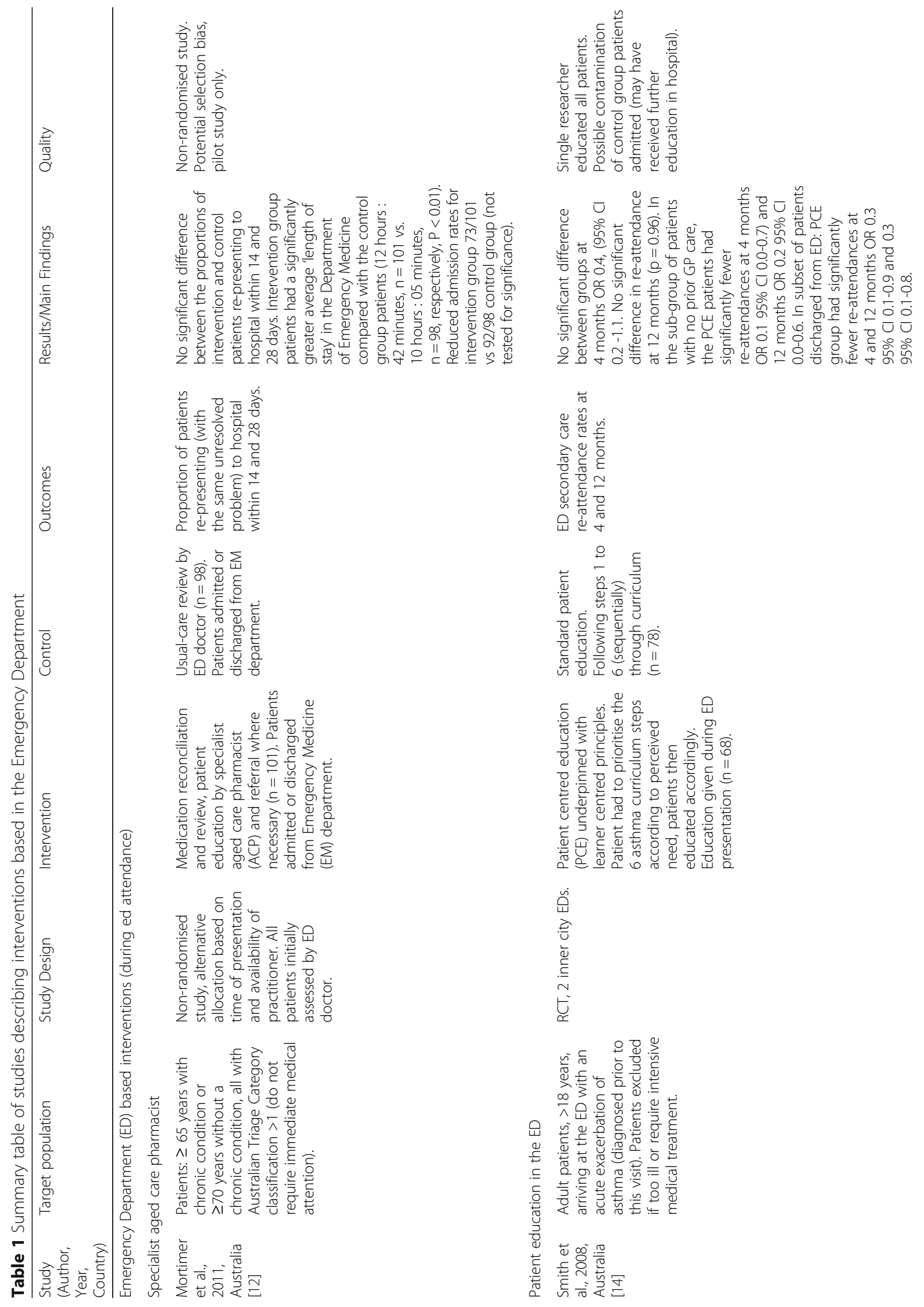




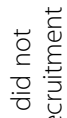

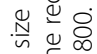

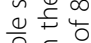

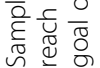

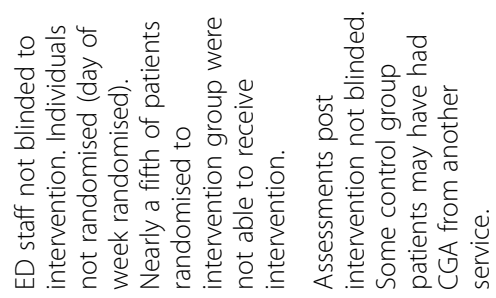

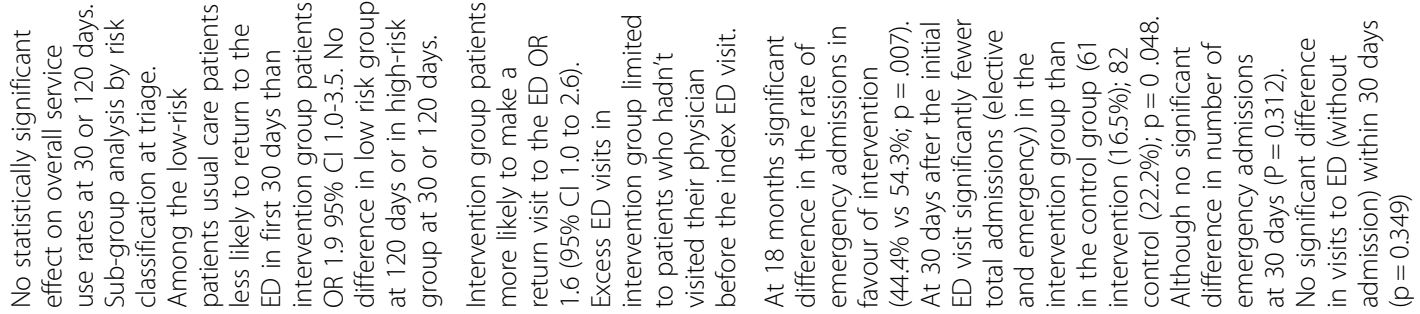

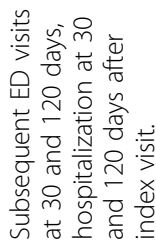

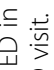

오누

党离

密兵

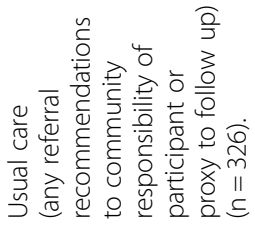

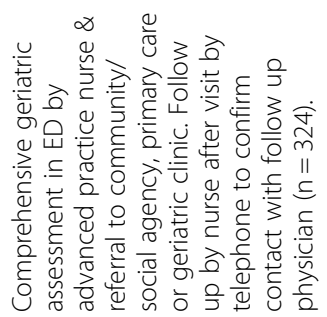

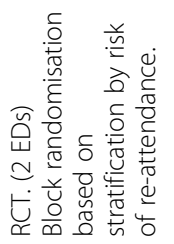

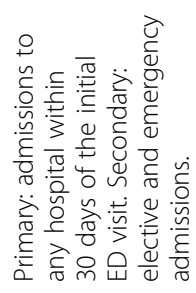

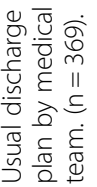

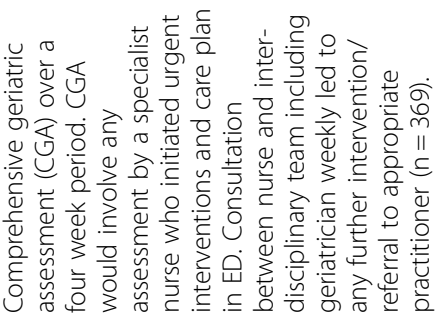

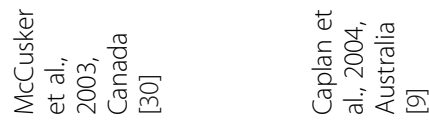

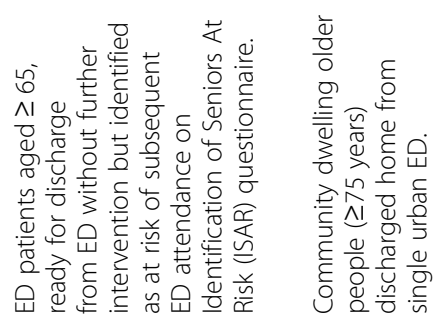




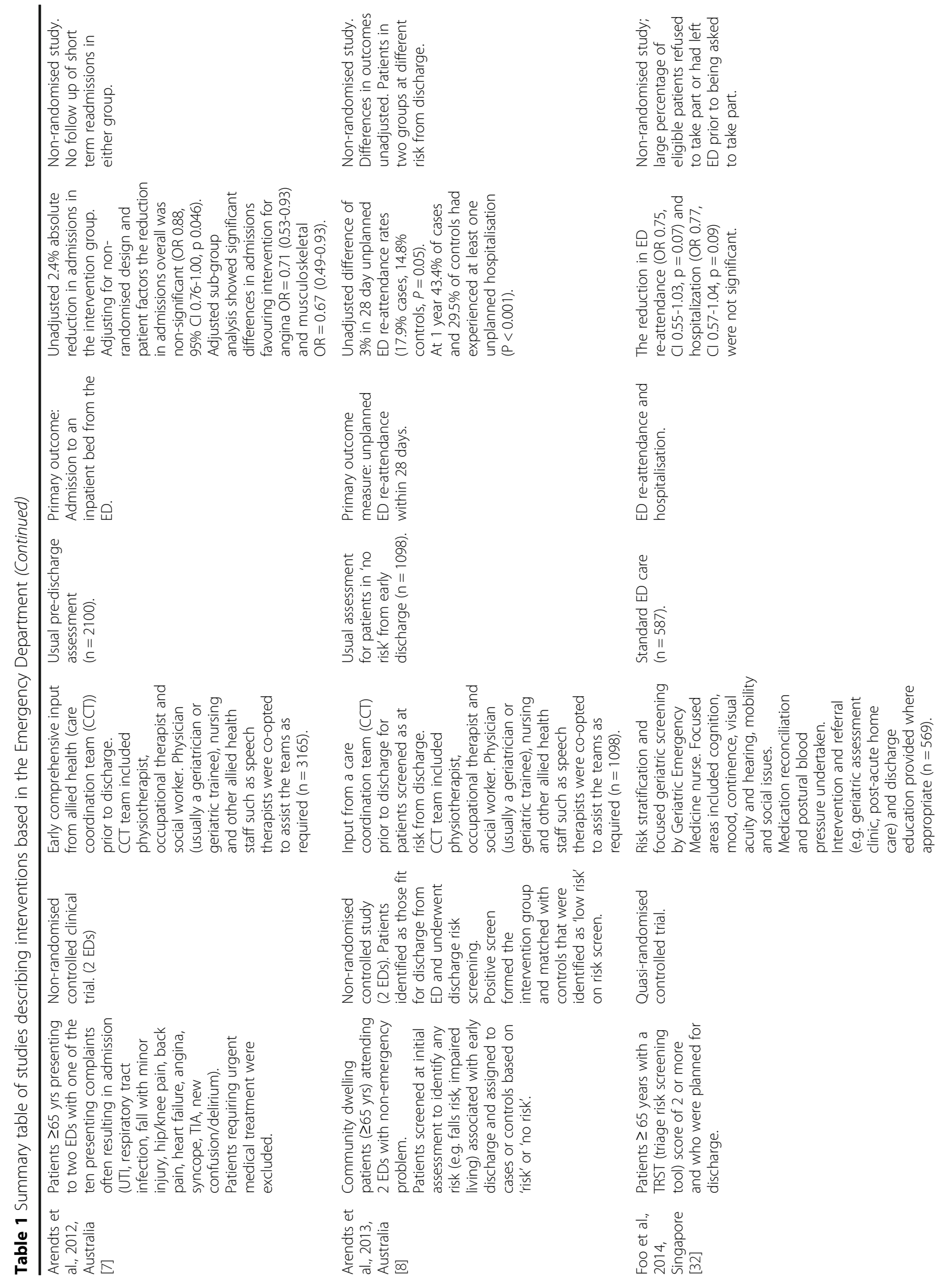




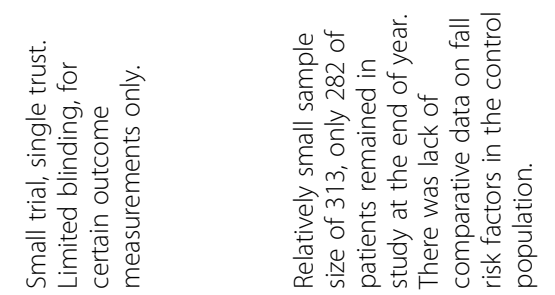

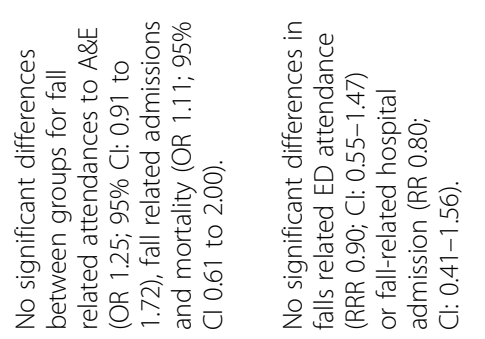

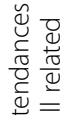 \\ 奇离}

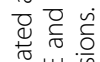

竞崖崖

จ

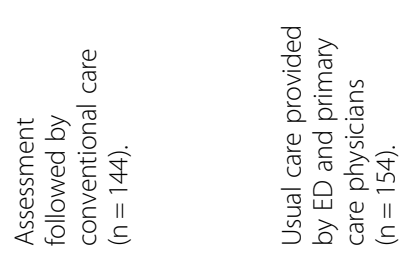

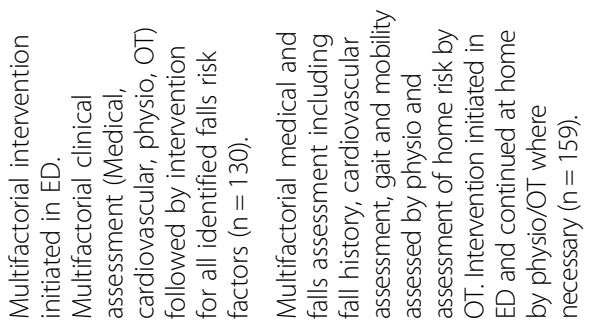

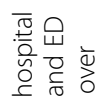

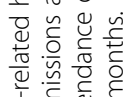

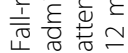

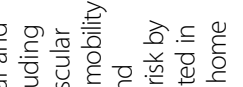

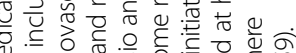

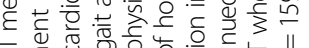

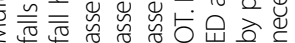

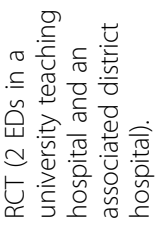

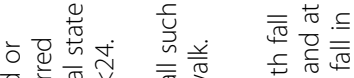

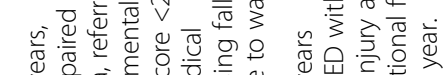

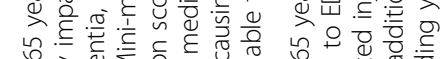

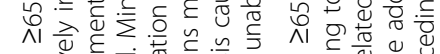

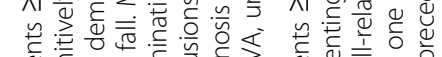

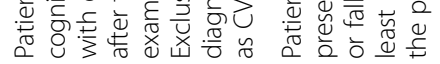

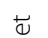

일

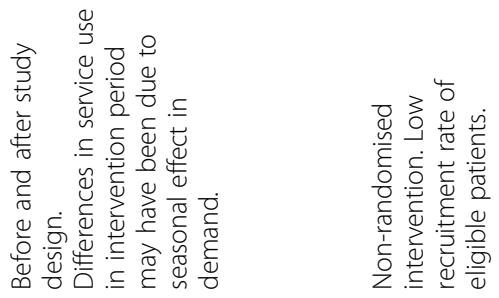

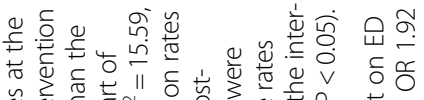

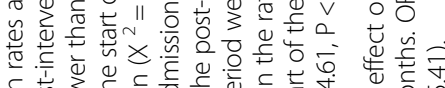

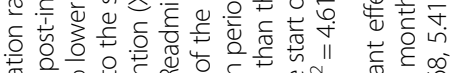

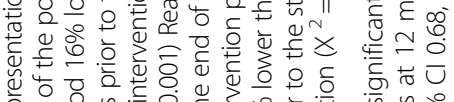

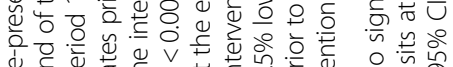

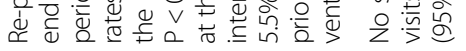

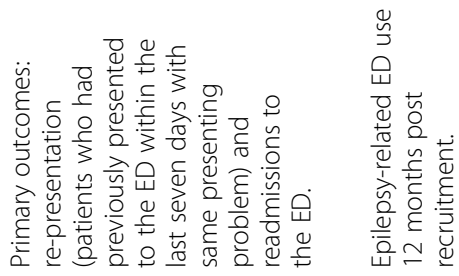

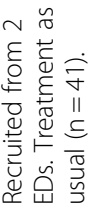

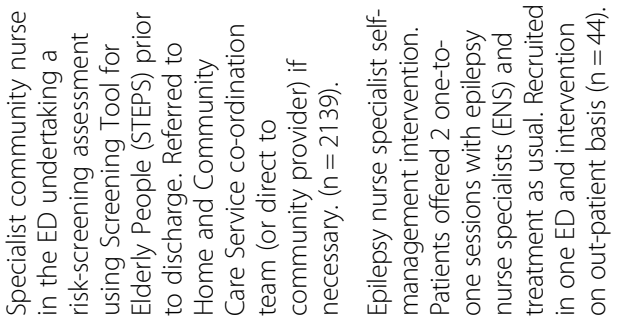

ธิ
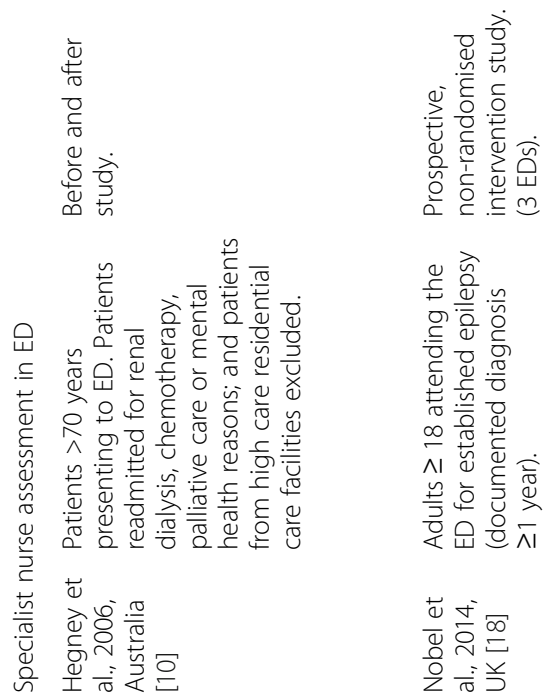

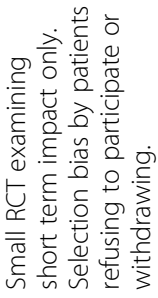

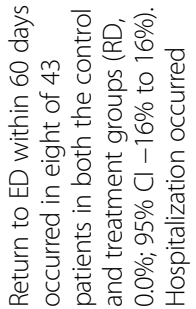

ำ

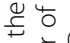

눤

劳

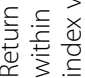

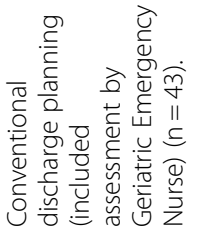

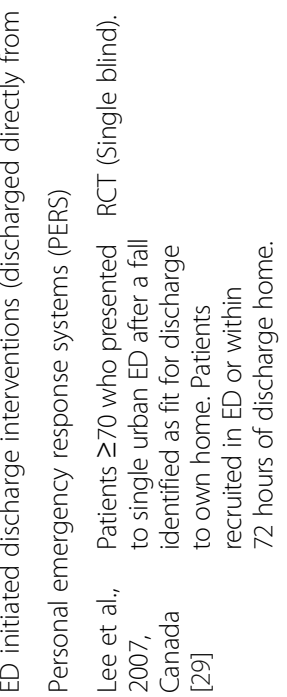




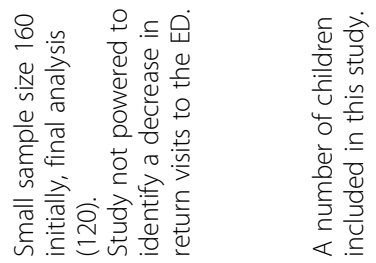

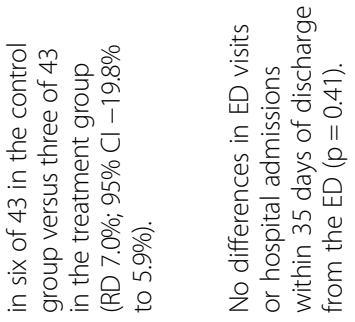

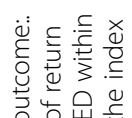

증

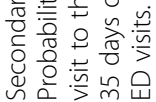

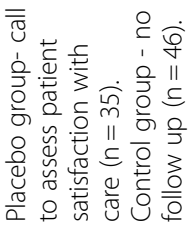

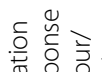

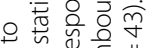

ह

考. 总

屯ั

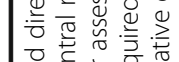

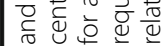

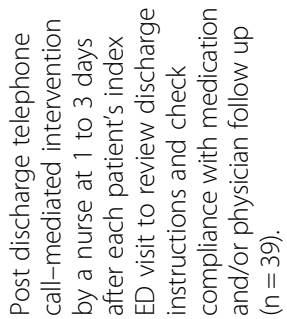

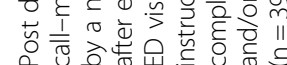

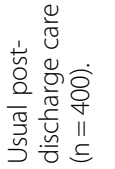

ㄴำ

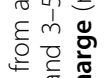

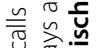

옥운

उ文㐫

产饴壳

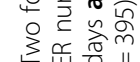
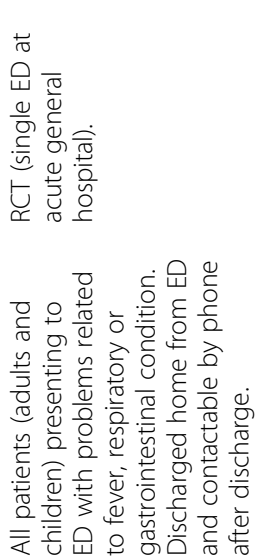

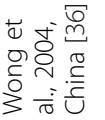

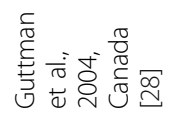

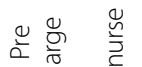

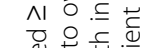

웡

뉻뭉

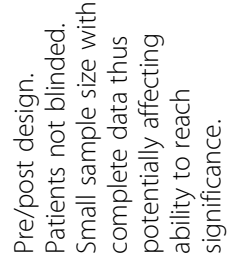

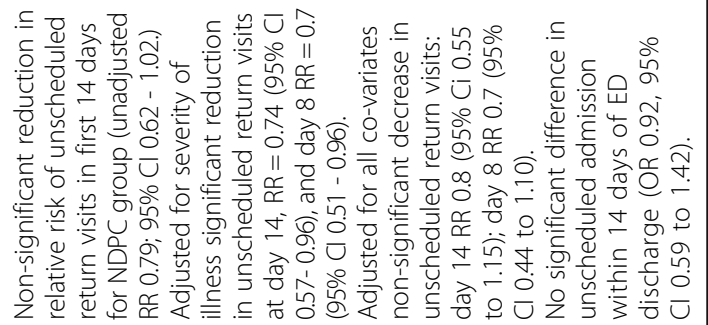

䒿

ऐ士

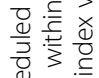

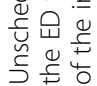

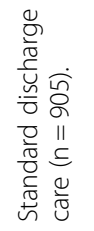

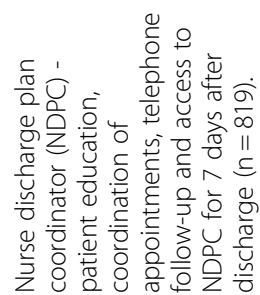

㝘总

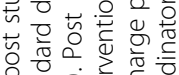

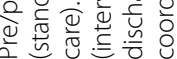

离

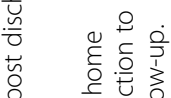

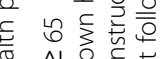

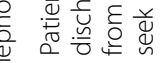

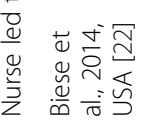

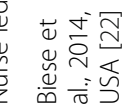

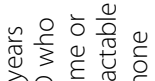

순므오웡

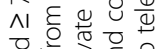

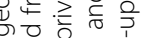

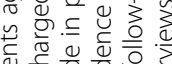

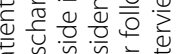

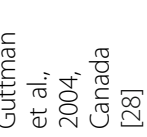




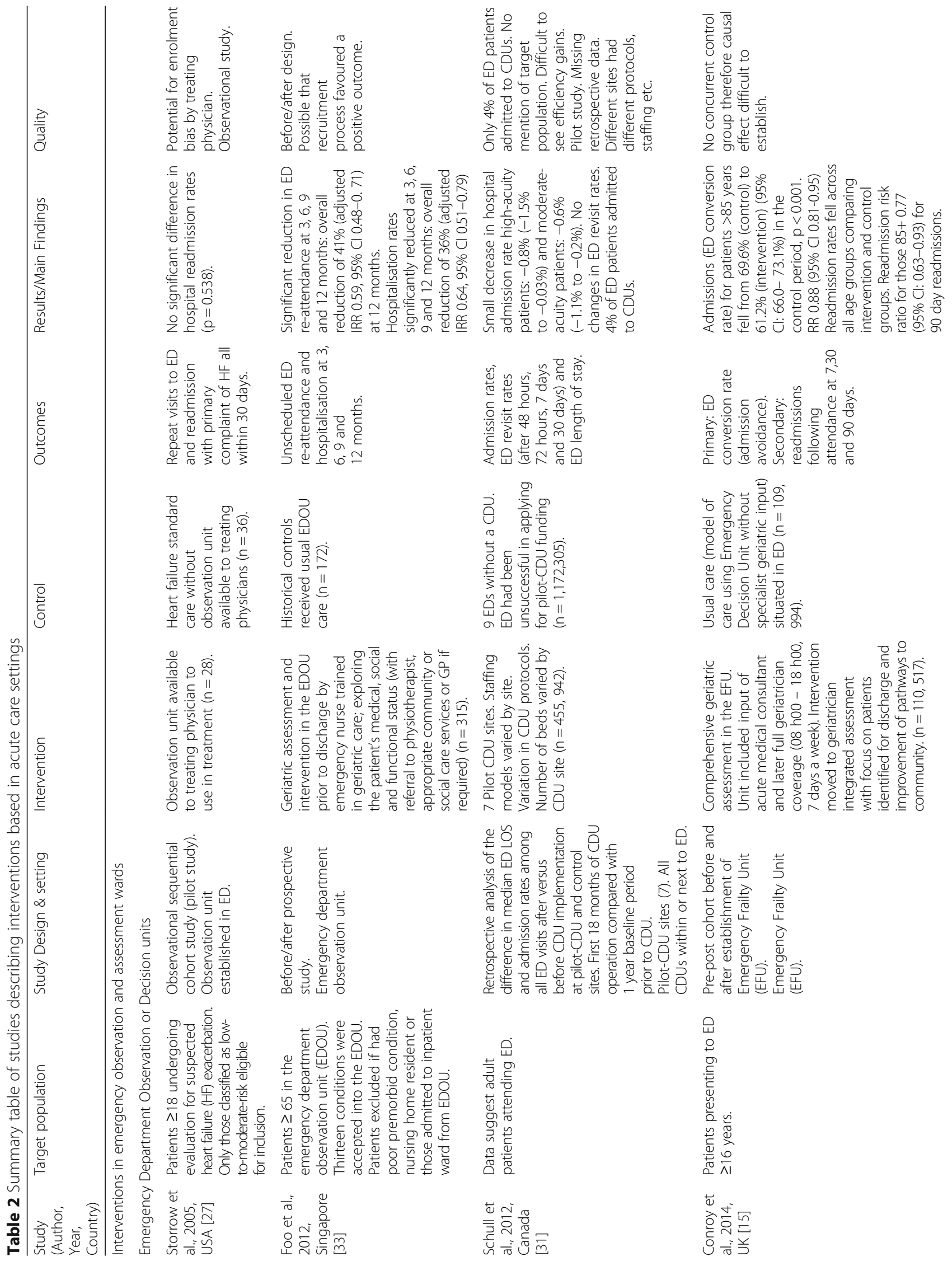




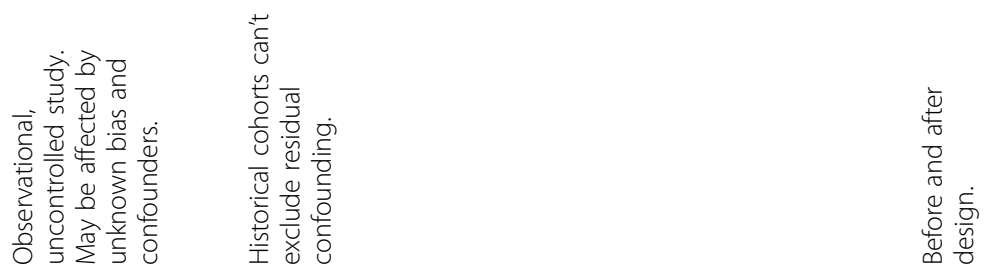

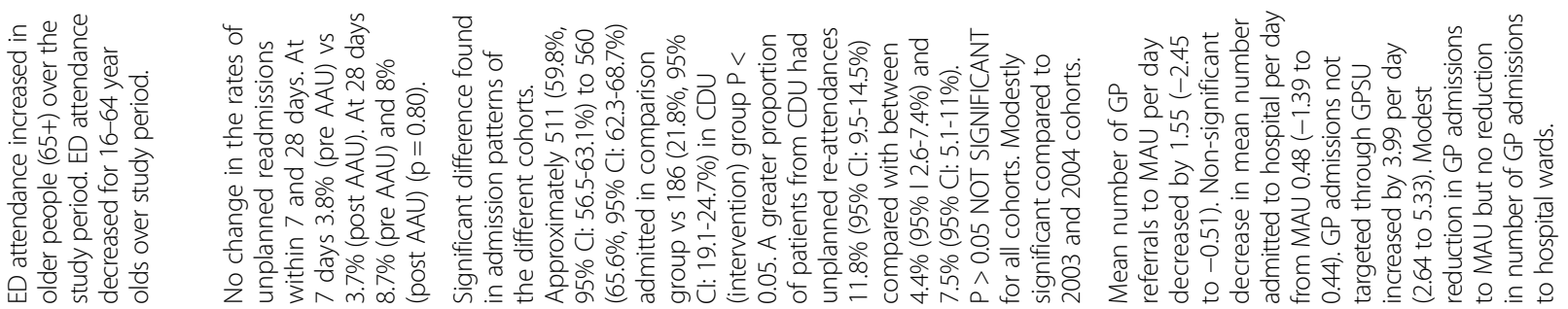

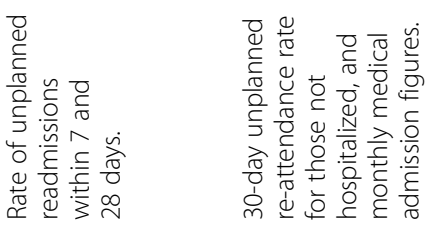

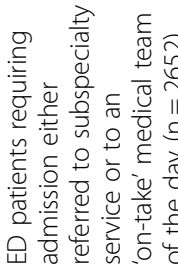

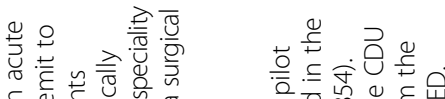

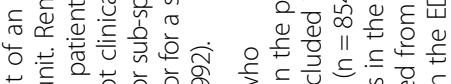

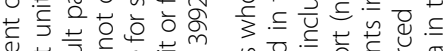

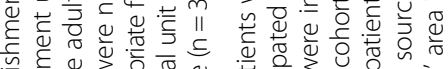

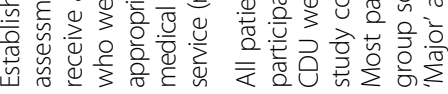

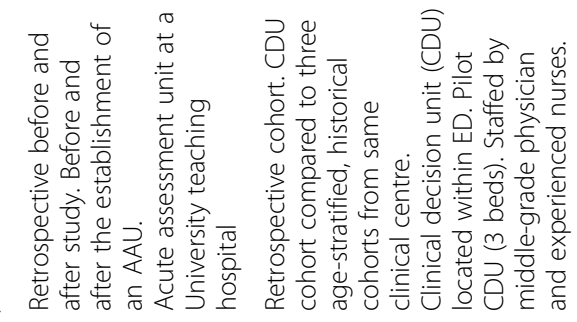

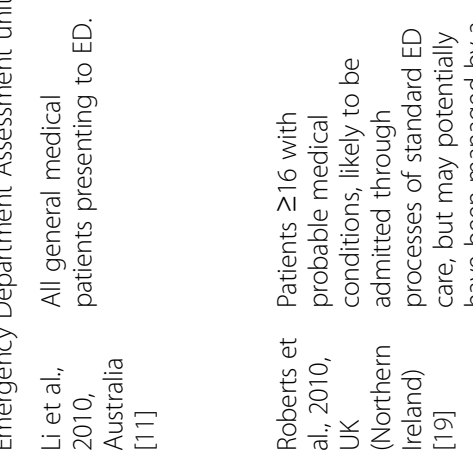

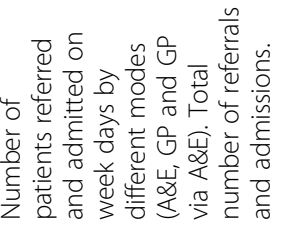

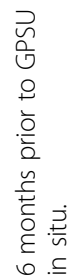

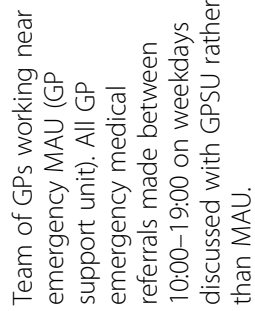

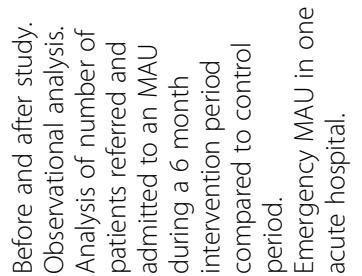

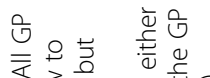

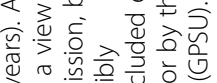

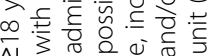

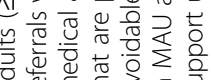

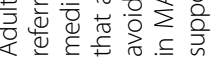

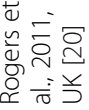




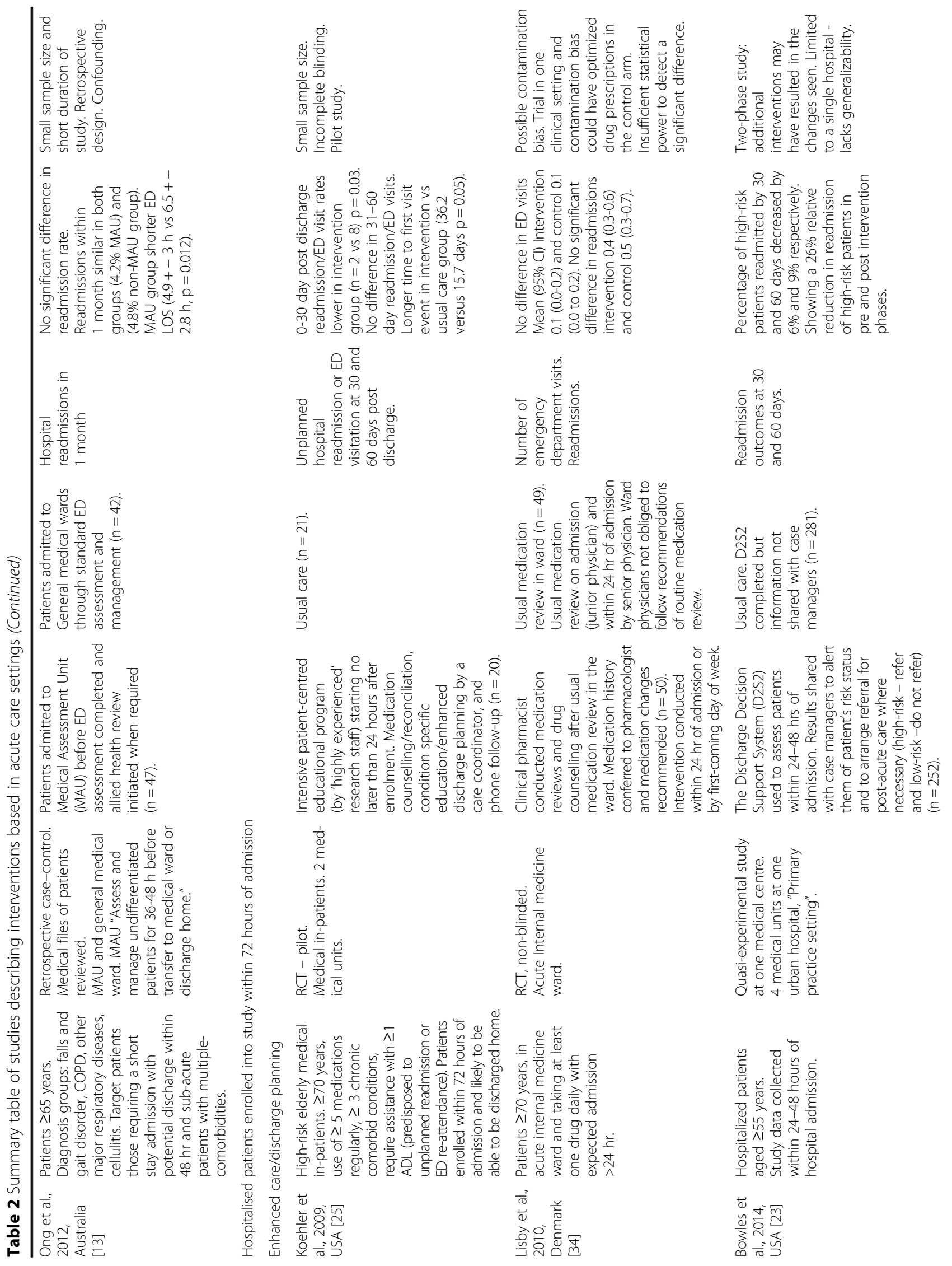




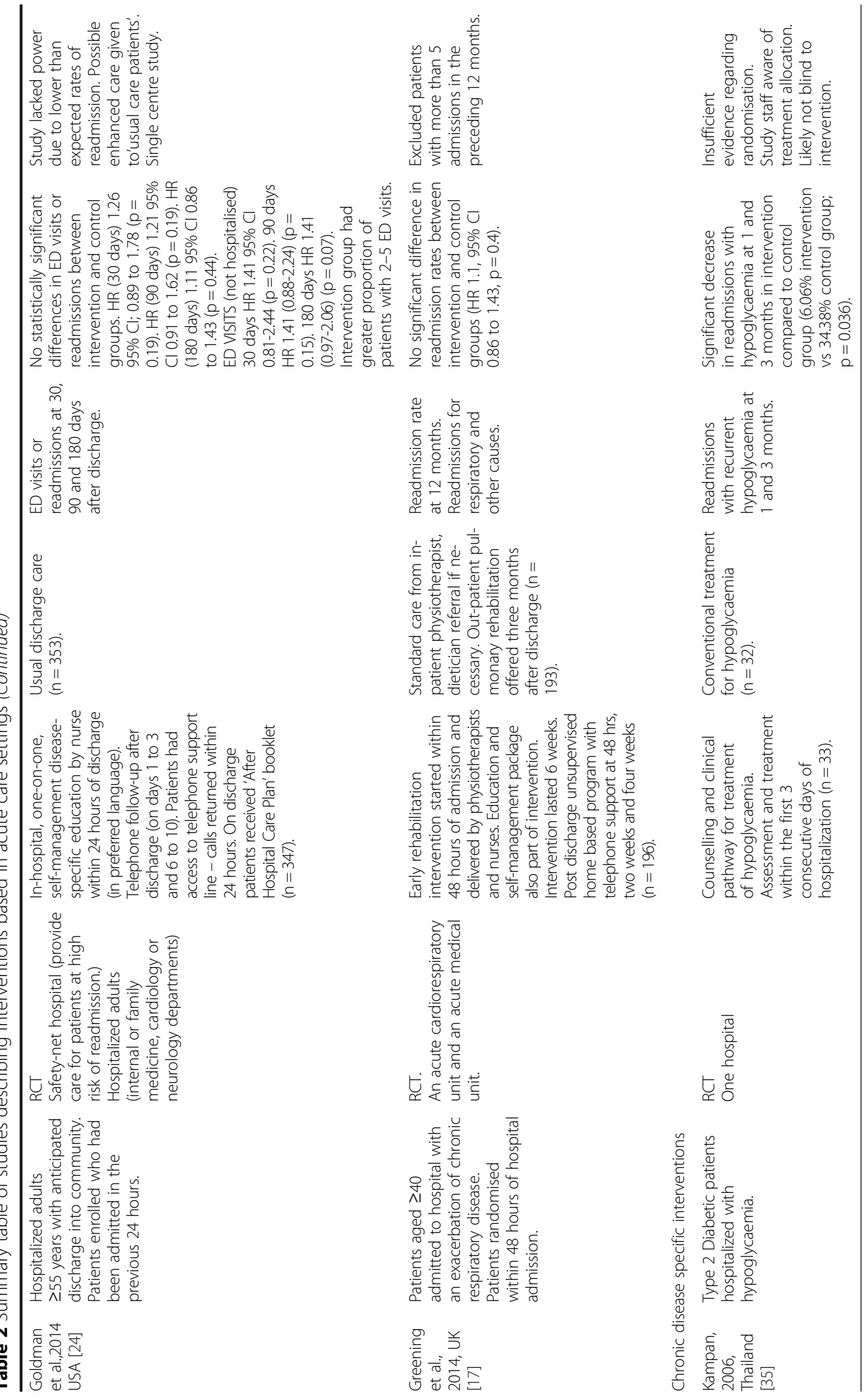


Studies that were exclusively of children attending the ED were excluded. The included evidence was restricted to countries within The Organisation for Economic Cooperation and Development (OECD) to ensure relative health system comparability to the United Kingdom (UK) National Health Service (NHS) and needed to be an English language publication.

Two authors (AS and EH) conducted the database searches. Two reviewers (SHC and $\mathrm{EH}$ ) undertook an initial title and abstract screen, using the review's inclusion and exclusion criteria. A third reviewer (CO) undertook a random screen of $10 \%$ of these and any discrepancies were resolved through discussion with this third reviewer. The full texts of all potentially eligible papers were reviewed by two reviewers ( $\mathrm{CO}$ and $\mathrm{SHC}$ ) and the final list of papers was agreed by consensus.

\section{Data extraction}

Three reviewers (CO, SHC and $\mathrm{EH}$ ) extracted data into standardised data extraction forms. The following data was extracted for each study: standard bibliographic information; target population; study setting; study design; description of the intervention; description of the control; reported outcomes and relevant study findings. Information on the study quality was also extracted. A $10 \%$ sample of papers was cross-checked between reviewers to ensure accurate data extraction.

\section{Assessment of quality}

Quality assessment of each paper was undertaken by the reviewers extracting the data. This assessment included a review of each paper according to the Critical Appraisal Skills Programme (CASP) checklist appropriate for the study design being reported [6]. The assessment of quality was further informed by the limitations as reported by the authors of the studies under review.

\section{Data synthesis}

Data for this review was extracted into tabular form and used to inform the narrative review. The considerable heterogeneity of the included studies did not lend itself to the consideration of a meta-analysis.

\section{Results}

\section{Study selection}

The database search for this review identified 4545 references; after removal of duplicate references 3216 unique references were identified. Of these, the full texts of 62 papers were examined and 15 papers included. Fifteen additional papers were included from those identified through additional search strategies - nine papers from citation searching and six were identified from the reference lists of included papers. Having sent the final list of included papers to experts within the field of emergency and acute medicine, no additional papers were identified. In total 30 papers met the inclusion criteria and are included in this review. Figure 1 details the process of study identification and final inclusion.

\section{Characteristics of the reviewed studies}

The thirty papers included in this study all describe studies that enrolled or conducted an intervention with patients on the 'journey' from ED arrival to in-patient ward admission (within $72 \mathrm{~h}$ of admission). Of these studies 19 were intervention studies (14 randomised controlled trials (RCTs)) the remaining 11 were controlled observational studies. The majority (8) of the papers were conducted in Australia [7-14]. Seven studies were conducted in the UK [15-21], six in the USA [22-27], four in Canada [28-31], two in Singapore $[32,33]$ and one each in: Denmark [34], Thailand [35] and China [36]. Study sample sizes ranged from 41 patients (pilot RCT) to 1, 628, 247 patient records in a retrospective analysis.

Sixteen studies were set in the ED and the remaining 14 studies were conducted in an observation unit, acute assessment ward or in-patient ward. The study characteristics as well as the principle findings of each study are summarized in Tables 1 (ED) and 2 (Acute care). Emergency department interventions were pragmatically categorised into three groups, according to the stage of the patient's journey during which the intervention took place. These categorizations included: interventions that took place during the ED attendance; interventions which were initiated in the ED and included a component in the community and post-discharge interventions which were initiated in the ED.

In order to classify the interventions according to where they occurred on the patient journey after ED presentation the following definitions, as proposed by Cooke et al., [37] have been used. Papers were classified according to the name given to the study setting by the author or the length of time the patient was anticipated to be in a particular setting as reported in the study.

\section{Assessment unit/ward}

An area where emergency patients are assessed and initial management undertaken by inpatient hospital teams. The patient is only in this area while early assessment is made, for example, up to $12 \mathrm{~h}$ and is then moved to another ward.

\section{Observation ward}

An area where patients can be observed or have early investigation/management within the A\&E [Accident and Emergency] department. Patients are admitted to this area with an expectation of discharge within $24 \mathrm{~h}$. 


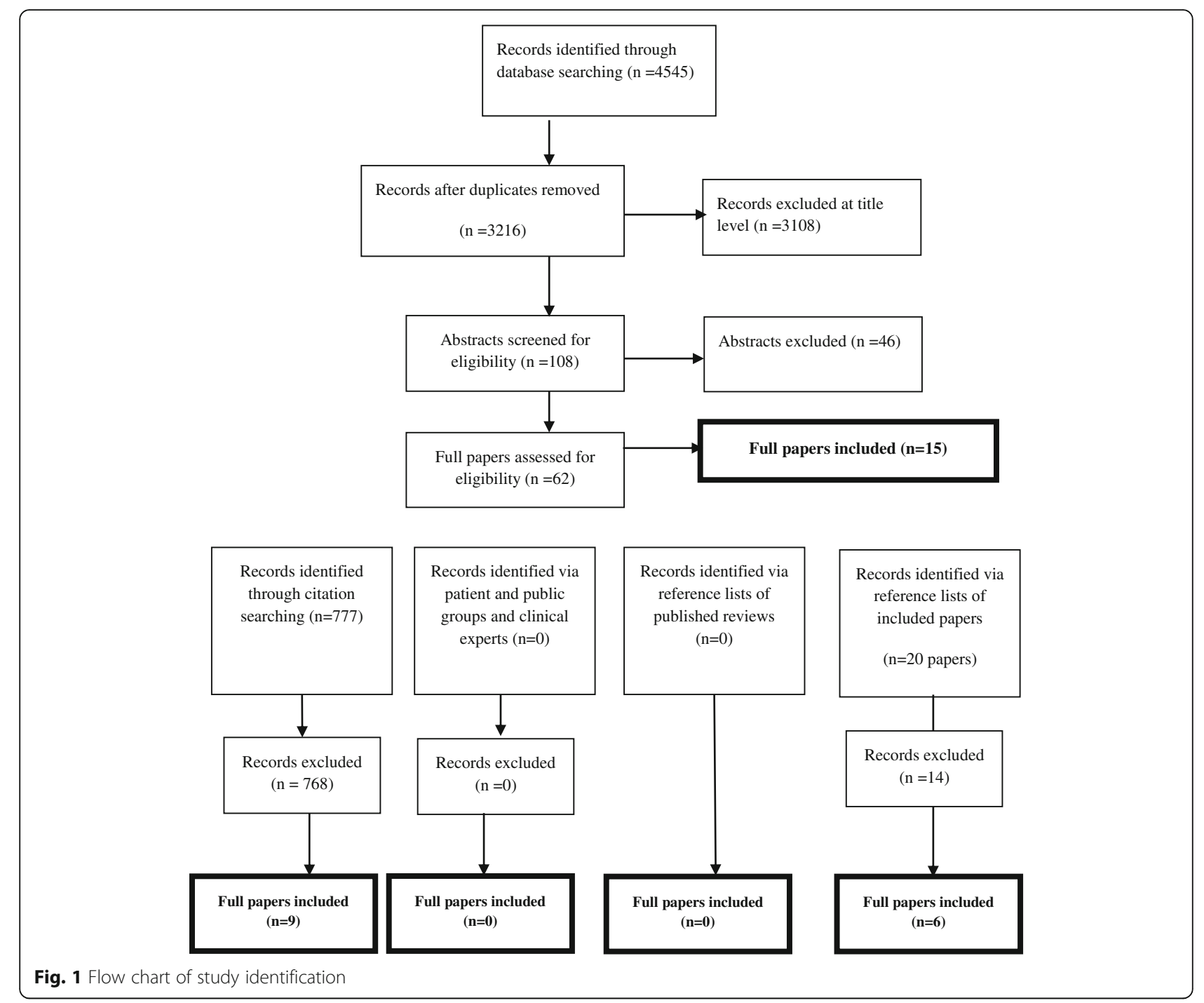

\section{Admission ward}

A ward to which people are admitted after clinical assessment for their continuing management [37].

\section{ED results}

Of the 16 studies based in the ED, two studies reported on interventions that took place during ED presentation, ten were studies that were initiated in the ED and include a component in the community and the remaining four studies were post-discharge interventions started in the ED. Of these 16 studies, 13 interventions targeted patients 65 years or older $[7-10,12,16,21,22,26,28-30,32]$, two included all adults over 18 years $[14,18]$ and one reported on both adults and children attending an A\&E [36]. Fifteen papers set in the ED measured ED attendance, six of these also measured hospital admission (including readmission) as outcomes; one paper reported hospital admission only.
ED based interventions (occurring during ED attendance)

Two studies described interventions that took place during the patient's time in the ED [12, 14]. One of these studies, which was non-randomised, involved the introduction of a specialist aged care pharmacist to provide medication reconciliation and review as well as patient education to elderly patients [12]. This study was not effective in reducing ED re-attendance but showed a possible reduction in admission rates for the intervention group [12]. However, this result was not tested for significance. The other study, set in the ED, was a randomised controlled trial, of patient centred education for asthmatic patients [14]. Results from this study suggest that at 4 months there was no significant difference in ED attendance between the intervention and control groups [14]. However, after controlling for general practitioner (GP) attendance the intervention group had significantly fewer ED re-attendances [14]. 


\section{ED initiated interventions which include a post-discharge community component}

Ten studies initiated an intervention in the ED that involved a post-discharge community component [7-10, 16, 18, 21, 26, 30, 32]. Each intervention differed but could be grouped under the following headings (Table 1): comprehensive geriatric assessment; multi-factorial falls intervention or specialist nurse assessment. Nine out of these ten studies included patients over the age of 65 years. Of the ten studies in this setting, two were effective in improving their primary outcomes $[9,10]$, one of these was an RCT. The RCT had an intervention which involved comprehensive geriatric assessment over a four week period [9]. The other study provided specialist community nurse risk screening for elderly patients prior to discharge [10]. A further two studies initiated in the ED showed a paradoxical increase in intervention patients re-attending the ED $[8,30]$.

\section{ED initiated post-discharge interventions}

The third categorization included four studies where the intervention was initiated at ED discharge and included a component of follow up or monitoring post discharge $[22,28,29,36]$. These included a study of an intervention that used personal emergency response systems and a further three that provided a nurse led telephone or telehealth post discharge intervention. One study, which adjusted for severity of patient illness, found a significant reduction in unscheduled return visits following discharge facilitated by a nurse discharge plan co-ordinator [28]. A further study paradoxically found that intervention patients were significantly more likely to return to the ED within 30 days of initial attendance [36].

\section{Acute care setting \\ Results}

Within the acute care setting, four studies were conducted in observation wards or decision units [15, 27, 31,33], where the patient is expected to be discharged within $24 \mathrm{~h}$, and four were conducted in ED assessment units or wards $[11,13,19,20]$. The remaining six papers describe studies where the patients were enrolled within $72 \mathrm{~h}$ of hospital admission [17, 23-25, 34, 35]. Nine of the studies within the acute care setting targeted adult patients $[13,17,20,23-25,27,33,34]$ one study included patients from 16 years [15] and three studies included patients of any age meeting their other inclusion criteria $[11,31,35]$. All of the papers in the acute setting reported admission (including readmission) as an outcome, seven of these (50\%) also reported ED attendance as an outcome.

\section{$E D$ observation or decision units}

Of the studies set in observation wards or decision units, two evaluated complex interventions that involved geriatric assessment, multi-disciplinary team intervention and community referral and two evaluated the effectiveness of the unit/ward on the outcomes of interest. Two interventions, both before-after studies, were effective in reducing the review outcomes of interest: ED re-attendance [33] and hospital admissions (ED conversion rate) [15], one of these was also effective in reducing re-admissions [15]. Foo et al., [33], provided geriatric assessment and appropriate intervention in an emergency department observation unit with follow up referral where necessary. Conroy et al., [15], evaluated the establishment of an emergency frailty unit on patient admission and readmission.

\section{$E D$ assessment units/wards}

The interventions that took place within an ED assessment unit either assessed the establishment of the unit $[11,13,19]$ or assessed the impact of a general practitioner (GP) support unit within a medical assessment unit (MAU) [20]. One study, a retrospective cohort, showed a significant reduction in admissions in favour of the study group [19]. However, in this study a greater proportion of patients in the intervention group had an unplanned ED re-attendance [19].

\section{Hospitalized patients enrolled within 72 hours of admission}

The studies into which patients were enrolled within $72 \mathrm{~h}$ of hospital admission [17, 23-25, 34, 35] involved enhanced care or discharge planning [17, 23-25, 34] and one paper reported on a chronic disease specific intervention for Type 2 Diabetes [35]. All of the studies reported hospital readmissions as an outcome and three reported ED revisit rates [24, $25,34]$. Three studies showed a significant reduction in ED readmission [23, 25, 35]. One of these was an RCT which included Type 2 diabetic patients and offered counselling and a clinical pathway for the treatment of hypoglycaemia in comparison to usual care [35]. The second study which was also an RCT, but a pilot RCT, provided intensive patient-centred education for high-risk elderly medical inpatients [25]. The final study which showed effectiveness was a quasi-experimental design comparing a discharge decision support system to usual care [23].

\section{Discussion}

This rapid evidence synthesis has found limited evidence of interventions along the patient journey through the ED that are effective in reducing hospital admission and/ or ED attendance. This review provides a more in-depth review of the patient pathway from the ED to acute admission than a recent review which similarly found insufficient evidence to determine whether services in the ED reduced unplanned admissions [5]. The interventions included in this evidence synthesis are of varying complexity, often comprising a number of different components which may be unique to a particular study 
setting (such as assessment and discharge planning by different types of health professional, different discharge pathways and additional care). This means it is difficult to establish exactly which elements of an intervention are impacting on outcomes which affect the generalisability of study findings.

In addition, the nature of the health problems and severity of illness among patients in the included studies varied greatly and may impact on the degree to which the interventions were effective. The type of health problem, and severity of the presenting condition, plays a large role in determining whether or not a patient is eligible for an intervention; what the nature of this intervention is; and where this intervention occurs within the healthcare system. Some studies included all adult patients attending $[11,15,31]$ while others risk stratified patients and only included those of low-moderate risk [27]; only those at high-risk [25] or those with potentially avoidable admissions $[19,20]$. The selection of 'high-risk' patients or those with poor baseline health with a background of chronic illness may be a reason for lack of intervention effect if the underlying chronic conditions increase the risk of admission $[8,26]$. In contrast Lee et al., [29], did not restrict their patient sample to 'high-risk' patients and suggest that had they chosen the group most likely to benefit from the intervention a positive intervention effect may have been seen.

What is apparent from the study findings is that high quality, prospective research is needed looking at complex interventions within the ED and acute care setting to reduce ED attendance or unplanned admission. In developing interventions researchers need to be guided by existing evidence regarding what may be effective; should ideally use randomised control trial methodology and include a pilot phase [38]. Furthermore, the intervention should be evaluated using an appropriate choice of outcome measures that provide an adequate assessment of the success of the intervention. The successful interventions included in this review include a number of features that may have contributed to their effectiveness and these warrant further high quality research.

Firstly, the literature suggests that ED initiated interventions that include comprehensive assessment or screening and community follow-up or referral have aspects that may have contributed to their effectiveness. The majority of the included studies (19/30) targeted their interventions at adults $>55$ years highlighting the focus on elderly care patients. Three studies that were effective in reducing admissions all included elderly patients, involved assessment by a specialist nurse and provided further treatment and referrals to appropriate providers $[9,10,28]$. These studies suggest that assessment and management of older people at risk of admission can improve their health outcomes. Accurate identification of patients in need of community support by trained nurses and services with appropriate follow up care may be effective in reducing ED attendance and hospital admission rates. Despite the promise that these interventions hold, the findings are not supported by Mion et al., [26], who reported no statistically significant effect on overall service use rates. This study intervention may have been weakened by a lack of advance practice nurse involvement after follow up which makes comparison with other studies difficult.

Secondly, the results suggest that the qualifications and specialties of the assessing and treating team members may impact on service utilization outcomes. A specialist nurse rather than a triage nurse, used in the intervention by Hegney et al., [10], impacted positively on service utilization. Guttman et al., [28], support this idea. In their intervention, study nurses were selected for their expertise in nursing care and had a minimum of 5 years nursing experience within acute care. This is important as the complexity of discharges and the hurried discharge conditions often present in the ED may be beyond the scope of a primary ED nurse [28]. In addition, as well as the usual emergency physicians, the clinical leads in Conroy et al's., [15], paper included geriatricians and emergency medicine nurses with additional training in geriatric syndromes and manual handling. Ensuring that team members were appropriately trained to manage and treat or refer patients appropriately may have contributed to the effectiveness of some of the included interventions.

A systematic review that looked at geriatric specific interventions on ED utilization found that the source of patients (ED, out-patient or home care setting) and the type of intervention impacted on the utilization rates [39]. Studies which recruited patients in the ED had little effect on ED utilization, partly, the authors believe, related to the limited follow-up duration for patients discharge from the ED and the difficulty in facilitating appropriate community follow-up and referrals from the ED [39]. Given that only two of the 16 ED based studies in our review were effective in reducing ED attendances or admissions (and a further two on sub-group analysis) may suggest that intervention location may have impacted on these study results. It may be the case that interventions should be trialled away from the time pressured environment of the ED and within observation or assessment wards to reduce unplanned admissions [37]. For patients discharged directly from the ED allowing sufficient time to plan the discharge care of patients may reduce the proportion of unscheduled ED return visits.

Observation and assessment wards, allow a greater length of time to assess and manage patients compared to the ED, and this additional time may have contributed to the positive findings of interventions to prevent reattendance and readmission in these settings. Older patients who receive comprehensive geriatric assessment, 
allied health intervention and referral prior to discharge, from an observation unit have decreased ED utilization $[15,33]$. Allowing a greater length of time to assess and manage patients enables complaints, other than the primary complaint, to be addressed and these healthcare needs met resulting in reduced ED reattendance and hospitalisation [33]. As it is not possible to provide comprehensive geriatric assessment to all patients, and for many this would be unnecessary, it is important that these interventions are targeted to high-risk patients [33].

Lastly, patient centred education within the ED may offer promise for specific chronic diseases. The results from the study by Smith et al., [14], found no significant difference in ED attendance rates although, after controlling for GP attendances, the intervention group had significantly fewer re-attendances. Educating patients according to their specific needs, guided by a curriculum, may be useful in reducing re-attendances to the ED as their healthcare needs are met. This finding is echoed in a Cochrane review that summarises education interventions for asthma in the ED which also suggests that hospital readmissions may be reduced through education interventions for asthmatics although the generalisability of the findings need to be confirmed in larger, multicentred trials [40].

The interventions initiated within $72 \mathrm{~h}$ of patient admission have aspects that are similar to the above findings. Interventions that involved patient education, enhanced discharge and included patient follow up after discharge have been shown to decrease readmission and ED visits [25]. In addition, when high-risk patients are identified and their needs are met, including sufficient time to work with patients and families to agree a workable care plan, readmission rates have been seen to decrease [23].
Interventions that targeted specific chronic conditions were limited to four studies. The target populations included patients with: asthma [14], epilepsy [18], heart failure [27] and Type 2 diabetes [35]. The heterogeneity of the patient groups and the interventions precludes making meaningful statements about what is effective in chronic disease management. Patient education and specific clinical pathways require further research in the acute care setting.

It is also important to discuss the paradoxical increase in ED re-attendance and hospital admission that is evident in some of the included studies. Three ED based interventions had this effect $[8,30,36]$. The reasons for this paradoxical increase may be that greater assessment and screening of patients sensitizes patients to health problems and motivates them to seek healthcare and access further services [36]. McCusker et al., [30], also suggest that this increase may be as a result of lack of access to primary care services which is a known predictor for increased ED utilization. These findings have also been seen in a systematic review which concludes that while ED based interventions may show promise they can have the unintended consequence of increased demand on these services [41].

The interventions included in this study can be considered as complex interventions, which include several components [42]. It is acknowledged that interventions classified as ineffective in this review does not necessarily mean that the intervention was ineffective but the findings may be as a result of process failures, how the intervention was implemented or whether the follow-up time was sufficient to provide an adequate assessment of the success or failure of an intervention [38]. Furthermore, many of the interventions included in this study had beneficial effects on other service related outcomes, for example: decreased hospital length of stay $[11,35]$ or increased contact with PHC following discharge [22]. These outcomes are not

\section{Key aspects of interventions that warrant further research}

- Comprehensive assessment and screening of elderly patients attending the ED may be effective in to preventing hospital admission and ED attendance.

- Follow up of patients after discharge (from ED or acute setting) may reduce ED attendance and readmission rates.

- Senior staff who are appropriately trained to manage and treat or refer complex patients appears to aid in preventing hospital admission.

- Interventions that are trialled away from the time pressured environment of the ED may be effective.

- Providing 'holding' areas for patients discharged directly from the ED to allow staff sufficient time to plan the discharge care of patients may reduce the proportion of unscheduled ED return visits.

- Further research regarding patient centred education within the ED for specific chronic diseases needs to be conducted.

- There is a need for high quality prospective studies in the UK setting.

Fig. 2 Key aspects of interventions, identified in rapid review, that warrant future research 
covered by our review and it is acknowledged that these interventions may be effective in reducing other important outcomes.

\section{Limitations}

The studies included in this rapid review were carried out in a variety of national settings with heterogeneous study designs and using different outcome measures and this limited our ability to synthesise the results of individual studies.

As this was a rapid review we did not score the quality of each individual included paper but took into account the limitations described by each author. The limitations of the papers were considered and these included nonrandomised studies or before and after design cohort studies which are more susceptible to certain bias than RCTs, such as selection bias [7, 9, 12]. Without evidence from randomised controlled trials, confounding and other methodological flaws cannot be discounted in evaluating the findings.

As this was a rapid review, with limited time frame, we did not attempt to identify all relevant evidence through an exhaustive search. Through a well thought out and devised search strategy we aimed to identify the key evidence of most relevance to our review question.

\section{Conclusions}

In the UK, emergency department attendances and emergency hospital admissions are continuing to increase. As the population ages medical admissions are also becoming increasingly complex as patients live longer with chronic medical conditions [1]. This review looked at the current evidence on interventions that reduce emergency hospital admissions and emergency department attendances with the aim of informing the design of new interventions to decrease service utilization.

A number of findings from this review (shown in Fig. 2) may be helpful in designing future interventions. Firstly, there is a need for high quality, prospective studies within the UK setting. Interventions targeted at high-risk patients, particularly the elderly, may reduce ED utilization and is worthy of future research. The development of future interventions should consider elements of interventions included in this review that were successful and may include: delivery by appropriately trained personnel and in an environment that ensures adequate time in which to assess and manage patients appropriately these elements may help to reduce the number of emergency admissions and the proportion of unscheduled return visits to the ED.

\section{Abbreviations}

A\&E: Accident and Emergency; CASP: Critical Appraisal Skills Programme; ED: Emergency Department; GP: General practitioner; MAU: Medical assessment unit; NHS: National Health Service; OECD: Organisation for Economic Co-operation and Development; RCT: Randomised controlled trial; UK: United Kingdom

\section{Acknowledgements}

Not applicable.

\section{Funding}

This research was funded by by the National Institute for Health Research Collaboration for Leadership in Applied Health Research and Care Yorkshire and Humber (NIHR CLAHRC YH). www.clahrc-yh.nihr.ac.uk. The views and opinions expressed are those of the authors, and not necessarily those of the NHS, the NIHR or the Department of Health.

\section{Availability of data and materials}

All data supporting the conclusions of this article are included within the article and the referenced literature.

\section{Authors' contributions}

All authors (SHC, CO, SM, AS, EH, SC and MW) contributed to the conceptualization and design of the review. $\mathrm{AS}$ and $\mathrm{EH}$ conducted the database searches. Two reviewers ( $\mathrm{SHC}$ and $\mathrm{EH}$ ) undertook an initial title and abstract screen, using the review's inclusion and exclusion criteria. A third reviewer $(\mathrm{CO})$ undertook a random screen of $10 \%$ of these and any discrepancies were resolved through discussion with this third reviewer. The full texts of all potentially eligible papers were reviewed by two reviewers ( $\mathrm{CO}$ and $\mathrm{SHC}$ ) and the final list of papers was agreed by consensus. SC drafted the initial manuscript and all authors participated in manuscript revisions. All authors (SHC, CO, SM, AS, EH, SC and MW) read and approved the final manuscript.

\section{Competing interests}

The authors declare that they have no competing interests.

\section{Consent for publication}

Not applicable.

Ethics approval and consent to participate Not applicable.

\section{Publisher's Note}

Springer Nature remains neutral with regard to jurisdictional claims in published maps and institutional affiliations.

\section{Author details}

'School of Health and Related Research (ScHARR), The University of Sheffield, Sheffield, England. '2Sheffield Teaching Hospitals NHS Foundation Trust, Sheffield, England. ${ }^{3}$ Doncaster and Bassetlaw Hospitals NHS Foundation Trust, Doncaster, England. ${ }^{4}$ School of Health and Related Research (ScHARR), The University of Sheffield, Regent Court, Regent Street, Sheffield S1 4DA, UK.

Received: 26 November 2015 Accepted: 8 May 2017

Published online: 16 May 2017

\section{References}

1. National Audit Office. Emergency admissions to hospital: managing the demand. London: The Stationary Office; 2013. https://www.nao.org.uk/wp-wpcontent/ uploads/2013/10/10288-001-Emergency-admissions.pdf. Accessed 15 May 2017.

2. Blunt I, Bardsley M, Dixon J. Trends in Emergency Admissions in England 2004-2009. London: Nuffield Trust; 2010.

3. O'Cathain A, Knowles E, Maheswaran R, Pearson T, Turner J, Hirst E, Goodacre S, Nicholl J. A system-wide approach to explaining variation in potentially avoidable emergency admissions: national ecological study. BMJ Qual Saf. 2014:23(1):47-55.

4. Scott I, Vaughan L, Bell D. Effectiveness of acute medical units in hospitals: a systematic review. Int J Qual Health Care. 2009;21(6):397-407.

5. Purdy S, Paranjothy S, Huntley A, Thomas R, Mann M, Huws D, Brindle P, Elwyn $\mathrm{G}$. Interventions to reduce unplanned hospital admissions: a series of systematic reviews. In: Final Report: June 2012 edn. Bristol: NHS Bristol; 2012

6. Critical Appraisal Skills Programme (2014). CASP Checklist. [online] Available at: http://www.casp-uk.net/casp-tools-checklists. http://www.casp-uk.net/ checklists. Accessed 11 Nov 2014

7. Arendts G, Fitzhardinge S, Pronk K, Donaldson M, Hutton M, Nagree $Y$. The impact of early emergency department allied health intervention on admission rates in older people: a non-randomized clinical study. BMC Geriatr. 2012;12:8. 
8. Arendts G, Fitzhardinge S, Pronk K, Hutton M. Outcomes in older patients requiring comprehensive allied health care prior to discharge from the emergency department. Emerg Med Australas. 2013;25(2):127-31.

9. Caplan GA, Williams AJ, Daly B, Abraham K. A Randomized, Controlled Tria of Comprehensive Geriatric Assessment and Multidisciplinary Intervention After Discharge of Elderly from the Emergency Department-The DEED II Study. J Am Geriatr Soc. 2004;52(9):1417-23.

10. Hegney D, Buikstra E, Chamberlain C, March J, McKay M, Cope G, Fallon T. Nurse discharge planning in the emergency department: a Toowoomba, Australia, study. J Clin Nurs. 2006;15(8):1033-44.

11. Li JY, Yong TY, Bennett DM, O'Brien LT, Roberts S, Hakendorf P, Ben-Tovim DI, Phillips PA, Thompson $\mathrm{CH}$. Outcomes of establishing an acute assessment unit in the general medical service of a tertiary teaching hospital. Med J Aust. 2010;192(7):384-7

12. Mortimer C, Emmerton L, Lum E. The impact of an aged care pharmacist in a department of emergency medicine. J Eval Clin Pract. 2011;17(3):478.

13. Ong BS, Van Nguyen $H$, llyas M, Boyatzis I, Ngian VJJ. Medical Assessment Units and the older patient: a retrospective case-control study. Aust Health Rev. 2012;36(3):331-5.

14. Smith S, Mitchell C, Mitchell S, Bowler S. Standard versus patient- centred asthma education in the emergency department: A randomised study. Eur Respir J. 2008;31(5):990-7.

15. Conroy SP, Ansari K, Williams M, Laithwaite E, Teasdale B, Dawson J, Mason S, Banerjee J. A controlled evaluation of comprehensive geriatric assessment in the emergency department: the 'Emergency Frailty Unit'. Age Ageing 2014;43(1):109-14

16. Davison J, Bond J, Dawson P, Steen IN, Kenny RA. Patients with recurrent falls attending Accident \& Emergency benefit from multifactorial intervention a randomised controlled trial. Age Ageing. 2005;34(2):162-8.

17. Greening NJ, Williams JE, Hussain SF, Harvey-Dunstan TC, Bankart MJ, Chaplin EJ, Vincent EE, Chimera R, Morgan MD, Singh SJ, et al. An early rehabilitation intervention to enhance recovery during hospital admission for an exacerbation of chronic respiratory disease: randomised controlled trial. BMJ. 2014;349:g4315.

18. Noble AJ, McCrone P, Seed PT, Goldstein LH, Ridsdale L. Clinical- and cost-effectiveness of a nurse led self-management intervention to reduce emergency visits by people with epilepsy. PLoS ONE. 2014;9(6):e90789.

19. Roberts MV, Baird W, Kerr P, O'Reilly S. Can an emergency department based Clinical Decision Unit successfully utilize alternatives to emergency hospitalization? Eur J Emerg Med. 2010;17(2):89-96.

20. Rogers P, Ward L, Salisbury C, Purdy S. Does a general practitioner support unit reduce admissions following medical referrals from general practitioners? Qual Prim Care. 2011;19(1):23-33.

21. Shaw FE, Bond J, Richardson DA, Dawson P, Steen IN, McKeith IG, Kenny RA. Multifactorial intervention after a fall in older people with cognitive impairment and dementia presenting to the accident and emergency department: randomised controlled trial. BMJ (Clinical research ed). 2003;326(7380):73.

22. Biese K, Lamantia M, Shofer F, McCall B, Roberts E, Stearns SC, Principe S, Kizer JS, Cairns CB, Busby-Whitehead J. A randomized trial exploring the effect of a telephone call follow-up on care plan compliance among older adults discharged home from the emergency department. Acad Emerg Med. 2014;21(2):188-95.

23. Bowles KH, Hanlon A, Holland D, Potashnik SL, Topaz M. Impact of discharge planning decision support on time to readmission among older adult medical patients. Prof Case Manag. 2014:19(1):29-38.

24. Goldman LE, Sarkar U, Kessell E, Guzman D, Schneidermann M, Pierluissi E, Walter B, Vittinghoff E, Critchfield J, Kushel M. Support from hospital to home for elders: a randomized trial. Ann Intern Med. 2014;161(7):472-81.

25. Koehler BE, Richter KM, Youngblood L, Cohen BA, Prengler ID, Cheng D, Masica AL. Reduction of 30-day postdischarge hospital readmission or emergency department (ED) visit rates in high-risk elderly medical patients through delivery of a targeted care bundle. J Hosp Med. 2009;4(4):211-8.

26. Mion LC, Palmer RM, Meldon SW, Bass DM, Singer ME, Payne SM, Lewicki L, Drew BL, Connor JT, Campbell JW, et al. Case finding and referral model for emergency department elders: a randomized clinical trial. Ann Emerg Med. 2003;41(1):57-68.

27. Storrow AB, Collins SP, Lyons MS, Wagoner LE, Gibler WB, Lindsell CJ. Emergency Department Observation of Heart Failure: Preliminary Analysis of Safety and Cost. Congestive Heart Failure. 2005;11(2):68-72.

28. Guttman A, Afilalo M, Guttman R, Colacone A, Robitaille C, Lang E, Rosenthal S. An emergency department-based nurse discharge coordinator for elder patients: does it make a difference? Acad Emerg Med. 2004;11(12):1318-27.
29. Lee JS, Hurley MJ, Carew D, Fisher R, Kiss A, Drummond N. A Randomized Clinical Trial to Assess the Impact on an Emergency Response System on Anxiety and Health Care Use among Older Emergency Patients after a Fall. Acad Emerg Med. 2007;14(4):301-8.

30. McCusker J, Dendukuri N, Tousignant P, Verdon J, Poulin De Courval, Belzile E. Rapid Two- stage Emergency Department Intervention for Seniors: Impact on Continuity of Care. Acad Emerg Med. 2003;10(3):233-43.

31. Schull MJ, Vermeulen MJ, Stukel TA, Guttmann A, Leaver CA, Rowe BH, Sales A. Evaluating the effect of clinical decision units on patient flow in seven Canadian emergency departments. Acad Emerg Med. 2012;19(7):828-36.

32. Foo CL, Siu WW, Ang HK, Phuah M, Ooi C. Risk stratification and rapid geriatric screening in an emergency department - A quasi- randomised controlled trial. BMC Geriatrics. 2014;14(1):98.

33. Foo CL, Siu WYY, Tan TL, Ding YY, Seow E. Geriatric assessment and intervention in an emergency department observation unit reduced re- attendance and hospitalisation rates. Australas J Ageing. 2012;31(1):40-6.

34. Lisby M, Thomsen A, Nielsen LP, Lyhne NM, Breum-leer C, Fredberg U, Jørgensen H, Brock B. The Effect of Systematic Medication Review in Elderly Patients Admitted to an Acute Ward of Internal Medicine. Basic Clin Pharmacol Toxicol. 2010;106(5):422-7.

35. Kampan P. Effects of counseling and implementation of clinical pathway on diabetic patients hospitalized with hypoglycemia. J Med Assoc Thail. 2006;89(5):619-25.

36. Wong FKY, Chow S, Chang K, Lee A, Liu J. Effects of nurse follow- up on emergency room revisits: a randomized controlled trial. Soc Sci Med. 2004;59(11):2207-18.

37. Cooke MW, Higgins J, Kidd P. Use of emergency observation and assessment wards: a systematic literature review. Emerg Med J. 2003;20(2):138.

38. Craig P, Dieppe P, Macintyre S, Mitchie S, Nazareth I, Petticrew M. Developing and evaluating complex interventions: the new Medical Research Council guidance. Br Med J. 2008;337(7676):979-83.

39. McCusker J, Verdon J. Do geriatric interventions reduce emergency department visits? A systematic review. J Gerontol Ser A-Biol Sci Med Sci. 2006;61:53-62.

40. Tapp S, Lasserson TJ, Rowe B. Education interventions for adults who attend the emergency room for acute asthm. Cochrane Database Syst Rev. 2007:3:Cd003000

41. Katz EB, Carrier ER, Umscheid CA, Pines JM. Comparative Effectiveness of Care Coordination Interventions in the Emergency Department: A Systematic Review. Ann Emerg Med. 2012;60(1):12-23.e11.

42. Campbell M, Fitzpatrick R, Haines A, Kinmonth AL, Sandercock P, Spiegelhalter D, Tyrer P. Framework for design and evaluation of complex interventions to improve health. Br Med J. 2000;321(7262):694-6.

\section{Submit your next manuscript to BioMed Central and we will help you at every step:}

- We accept pre-submission inquiries

- Our selector tool helps you to find the most relevant journal

- We provide round the clock customer support

- Convenient online submission

- Thorough peer review

- Inclusion in PubMed and all major indexing services

- Maximum visibility for your research

Submit your manuscript at www.biomedcentral.com/submit
C) Biomed Central 